\title{
Article \\ Taking a Health Perspective on Roller Derby: A Qualitative Exploration of Women's Experiences
}

\author{
Jane Scullion (1) and Cathy Bulley *
}

Citation: Scullion, J.; Bulley, C.

Taking a Health Perspective on Roller

Derby: A Qualitative Exploration of

Women's Experiences. Women 2022, 2 ,

15-28. https://doi.org/10.3390/

women2010002

Academic Editor: Mary V. Seeman

Received: 10 December 2021

Accepted: 11 January 2022

Published: 20 January 2022

Publisher's Note: MDPI stays neutral with regard to jurisdictional claims in published maps and institutional affiliations.

Copyright: (c) 2022 by the authors. Licensee MDPI, Basel, Switzerland. This article is an open access article distributed under the terms and conditions of the Creative Commons Attribution (CC BY) license (https:// creativecommons.org/licenses/by/ $4.0 /)$.
School of Health Sciences, Queen Margaret University, Edinburgh (at Time of Study), Queen Margaret Drive, Musselburgh EH21 6UU, East Lothian, UK; jane.scullion@googlemail.com

* Correspondence: cbulley@qmu.ac.uk; Tel.: +44-0131-474-0000

\begin{abstract}
Although far fewer women exercise regularly than men, one women-dominated sport growing in popularity internationally is roller derby. A limited number of predominantly US-based and qualitative studies have explored roller derby. This Scotland-based qualitative study explored reasons for women starting, continuing, and stopping participation in roller derby in order to inform people involved in promoting physical activity for health benefits. Semi-structured interviews with six participants from a Scottish women's roller derby league were recorded and transcribed verbatim. Data analysis using Interpretative Phenomenological Analysis generated five super-ordinate themes. Most participants learned about roller derby from watching the sport on film, attending a bout (game), or word of mouth. The main motivators and benefits of participating in this sport were found to be challenge, enjoyment, increased confidence, health benefits, and motivation to exercise. Participants were empowered by involvement and motivated by community, team spirit, and support to develop. Despite high commitment, some women could not sustain team involvement due to barriers such as injury, changing life roles, and conflicting commitments-a lack of support was described when this happened. Greater inclusivity is needed to enable changing levels of participation as women's commitments change, to facilitate ongoing health benefits and inspire others.
\end{abstract}

Keywords: health; women; health promotion; sport; exercise; roller derby; motivators; barriers; empowerment

\section{Introduction}

It is well-established that taking part in physical activity can bring numerous health benefits [1], lowering chronic disease risk and improving psychological well-being [2]. This is of significance in many countries, including Scotland, where adult overweight and obesity rates are particularly high, especially in women $[3,4]$. Despite this, far fewer women than men exercise regularly internationally, which has public health implications [5]. This is exacerbated by inequalities in sports participation, which are evident internationally, and are problematic because sport has been identified as increasingly important to combat societal decreases in daily energy expenditure and related health implications. A survey of sporting activity in the 27 European Union member states found that 4 out of 10 people were not engaged in regular sport, with even fewer women [6]. In Scotland, only a fifth of women hold a sports club membership compared to a third of men [7]. Interestingly, however, growing numbers of women play roller derby in Scotland. Roller derby is a full-contact women's team sport played on roller skates. It is unique in having a grassroots, women-owned and operated organisational structure that does not fit within pre-existing institutions. This contrasts substantially with many women's sports that are often modelled on conventionally male sports. It is a relatively new and progressive sport with unique characteristics, marking it as an important case for understanding women's sports participation. This study aims to explore the reasons behind increasing roller derby participation in Scotland. We hoped to gain transferable insights that can be used to facilitate greater participation in sport, with positive health gains, among women. 
Numerous studies have focused on the challenges to women in relation to sports participation. More have focused on sports such as rugby and football that demonstrate aggression and physical contact, more often considered 'masculine' [8], while issues are also evident in various other sports, including mixed martial arts and cycling $[7,9,10]$. There is evidence of different preferences, for example, with boys preferring more free play activities that involve object-control skills, which may have implications for the development of girls' perceived competence and self-confidence in relation to sport [11]. Life changes add to cultural and structural issues in challenging women's development of sporting identities and lifestyles. A study of the experiences of 28 Australian mothers of children under 5 years old was conducted through telephone interviews [12]. Women were strongly motivated by feelings of responsibility to their children. Promoting health behaviours through emphasising the responsibility to remain healthy for one's family is often used by health professionals. This can unhelpfully ignore the co-constructed aspects of health, leading to feelings of guilt and failure with reduced self-efficacy as people feel progressively less able to change behaviours [13]. Such impacts of cultural norms are likely to be prevalent in the UK also: stage of life and influences of family and peers have been found to impact on barriers to participation, and there is evidence across the UK that men spend more time in leisure activities than women [14].

In the face of these barriers, the competitive sport of roller derby stands out as it attracts thousands of women worldwide, with increasing participation in Scotland from the first league in 2007 to 19 leagues in 2018 [15]. Roller derby is a full-contact sport on quad roller skates that originated in America and developed in the 1930s when staged fights provided "entertainment" for live and/or television audiences, disappearing from the public's consciousness in the 1970s. In 2000, the sport was revived and reincarnated into a competitive sport [16], with predominantly women operated leagues. The Women's Flat Track Derby Association (WFTDA) was created: an international non-profit governing body for women's flat track roller derby. In 2018, there were 418 fully registered WFTDA leagues worldwide, and 46 apprentice leagues [17]. A more detailed history of roller derby is provided at: https:/ / wftda.org/history (accessed 19 January 2022). Over recent years, men and gender diverse skaters have increasingly played in mixed and co-ed leagues and men's teams. Playing on indoor oval tracks, games are fast-paced and skilful. Players called 'Blockers' use specific parts of their bodies to stop the opposing team's 'Jammer' (the point scorer) or assist their own Jammer through the 'Pack' (consisting of blockers from both teams) [18]. Games are composed of two 30-min halves, with each team skating five players at a time in shifts ('Jams') lasting two minutes [16]. A large volunteer team of game officials support bout days, including team bench staff, referees, and non-skating officials. Before the COVID-19 pandemic, roller derby was attracting a growing number of women in Scotland, with three female, two male, and two co-ed leagues across the country. One study [19] started the exploration of why women participate in roller derby in Scotland, however more depth of insight into the appeal of this unique sport is needed.

Roller derby has received little academic attention. On searching academic databases, more than ten qualitative studies explored experiences of women participating in contemporary roller derby. Hoskins and Hooker [20] quantitatively evaluated concussion in roller derby, while Eklund and Masberg [21] used mixed methods to investigate how participation in roller derby affects body image. Alexander [22] conducted an ethnographic mixed methods study exploring the roller derby subculture scene, also focusing on the contributions from non-skating members. Most qualitative studies are ethnographic and feminist in approach, for example, an in-depth ethnographic case study which offers sociological analysis of roller derby in Scotland [19]. These studies offer valuable insights into the sport, however, we sought to explore the literature from a public health lens, with interest in what draws women to the sport and enables them to sustain participation long-term.

Common themes emerged from the studies, discussing the benefits of participation. Feminist literature has drawn attention to male domination within the institution of sport. Roller derby is a unique example of a sport where women have defined the rules. Women 
described feeling more empowered due to feeling stronger, belonging to a community, and a sport that challenges traditional notions of femininity [16,23-27]. The do-it-yourself (DIY) ethos has been found to be crucial in explaining how women have managed to maintain control of the sport [25]. Roller derby is a sport owned by women, and women enjoy having control and a voice within the sport and organisations that they have created. Studies highlighted how women unapologetically take pride in attributes typically assigned to male athletes, such as toughness and aggression. It provides a unique space for women to embrace strength, competition, and aggressiveness [16,18,23,24]. Women have rejected traditional ideas that women are weak. Roller derby provides an alternative body evaluation system based on how bodies perform on the track rather than how they look $[16,23,28]$. Fewer studies have observed that women enjoyed the friendship, social bonding, and collective sharing of resources [16,29]. Current studies on roller derby largely explore the positive aspects of participation in this sport, and briefly discuss some of the barriers. Given that there are likely to be cultural differences, more studies outside the United States are required that explore reasons why women are drawn to this sport in the first place, and why they might drop out. Women's flat track roller derby is a rapidly emerging sport that may demonstrate unusual characteristics when compared with other sports and provide valuable insights to people involved in promoting physical activity and sports participation with a health-related focus.

Therefore, this qualitative study aimed to explore the barriers and motivators for women participating in roller derby in Scotland, using semi-structured interviews.

\section{Materials and Methods}

A qualitative approach enabled exploration of experiences and opinions of women participating in roller derby, focusing on insights into complex behaviours and influences on related choices. An interpretative phenomenological approach was taken to explore how people make sense of their life experiences [30]. Individual semi-structured interviews enabled in-depth insights in a safe environment [31]. Ethical approval was gained from the Queen Margaret University Divisional Research Ethics Committee prior to recruitment and data collection commencing.

\subsection{Participants}

This study was conducted through a single league with which the researcher was familiar due to her previous participation as a skater, enabling her to identify who would meet the inclusion/exclusion criteria. The researcher (J.S.) skated with the league for three years, until three years before the current study, retiring due to other commitments. Interviews were conducted in July 2016, when the league was ranked within the top 100 leagues globally. Despite the time gap between this and the current article submission, we believe there is a lack of research in the field and the lessons learned have become even more relevant due to the impacts of the recent pandemic on people's ability to participate in sport and leisure activities. This has further increased the need for insights into promotion of physical activity for women.

A participant number of between six and eight people was considered possible within the scope of this unfunded study, while still of value within a rigorous qualitative study. Eight people were invited to participate in order to optimise the likelihood of a participant number within this range and to ensure people with different types of experience were represented. Six people agreed to participate in face-to-face interviews. While this represents a relatively small participant number, it is well within the range in published phenomenological studies [32]. Depth of insight was sought in order to stimulate further work and the research approach of phenomenology is not consistent with the concepts of either generalisability or saturation [32]. Two women were sought from each of the three participant groups to ensure balanced and varied representation of experiences from those who could communicate sufficiently in English and: (1) had been participating for more than six months, after which league training is likely, (2) had stopped participating in roller 
derby, and (3) had been participating for two to six months (long enough to gain insight into motivations regarding ongoing participation). The average time spent with the league is between one and five years and participants who had been with the league for more than five years all held leadership roles.

Permission was provided by the Chair of the league which is a member of the WFTDA with 60-70 members. The league runs 2-3 $\mathrm{h}$ training sessions for most of the year-three times weekly for the A team (most skilled players) and twice weekly for all others. New skaters start learning the skills necessary to play roller derby in the Recruits stage. On successfully passing a written and practical exam, they move up to league training, with the opportunity for selection into one of two travel teams (A and B) which play others nationally and internationally. New league skaters will typically start playing in the B team.

The Chair of the league was approached by email to seek support for the study. Potential participants in Groups 1 and 2 were known to the researcher from attending training together, and the league Chair distributed study information to new skaters (Group 3). Potential participants received an invitation letter, information sheet, and response form with the principal investigator's (J.S.) contact details. If interested, they were asked to return consent forms and participation response forms within two weeks. Interviews were then arranged and conducted in a quiet room at the Glasgow Mitchell Library during July 2016.

\subsection{Data Collection Procedure}

Interviews lasted 45-90 min and were digitally audio-recorded. Participants were assured that they would not be identified in the study and any reporting and could withdraw from the interview at any time. Data protection principles were followed in transportation and storage of data. J.S. conducted all interviews and explained her role as independent from the League, emphasising the importance of the participants' experiences and views and her interest in gaining insight into their experiences. This limited the possibility of her prior involvement with the league creating communication barriers with participants but facilitated a rapport with participants. In case of concern, the researcher provided details of the relevant person within the league who could be contacted after the interview. The topic guide was developed collaboratively (J.S. and C.B.), using an inductive approach that focused on the study aims, which were informed by the literature and a public health lens. The questions were carefully designed to elicit the information desired according to the study aims without implying the views or assumptions of the researchers. The lead researcher carried out a pilot study with a peer to ensure that the questions were clear, inoffensive, and non-leading. Sample questions included: What is it like participating in roller derby? What influences you to attend training each week? Is there anything that gets in the way of participation? Participants were asked to review interview summaries to ensure that information had been appropriately interpreted.

\subsection{Analysis}

Interpretative Phenomenological Analysis (IPA) was used to enable a description of participants' experiences and interpretation of meaning. Thematic analysis was carried out using six steps described by Smith et al. [30]. Transcripts were read and re-read (step 1); ideas were then annotated in notes (step 2) that were grouped according to meaning as emergent themes (step 3). Connections across emergent themes were then sought (step 4). Steps 1-4 were repeated for each transcript and patterns sought. A more experienced researcher (CB) supported the analysis and reviewed a transcript sample to ensure rigour. This ensured that if there were differences of opinion in relation to emerging themes, collaborative discussion would enable the researchers to arrive at conclusions about where themes were distinct, how they should be defined, and which text supported them. Interrelationships, connections, and patterns from the transcripts were mapped, and connections and relationships between themes supported by the text were developed into super-ordinate themes, and a conceptual 
framework. Researcher reflexivity was incorporated at all stages to increase rigour of data collection and analysis.

\section{Results}

Respondents were 22 to 42 years old, all skaters from the same Scottish league, with duration of participation varying from three months to eight years. Two respondents had stopped participation in roller derby. Current skaters attended between 8 to 10 sessions a month. All respondents were physically active outside of roller derby. Interviews lasted between 45 and 90 min in length, with variation resulting from differences in participants conversational style and depth of reflection on the topic. Participants had learned about roller derby by watching a popular roller derby film called "Whip It" (two participants), word of mouth (two participants), or watching a bout (one participant). An overview of super-ordinate themes related to individual themes is illustrated in Figure 1 and each is explained in the sub-sections below. Pseudonyms are used, followed in brackets by the participation duration range into which the participant fits.

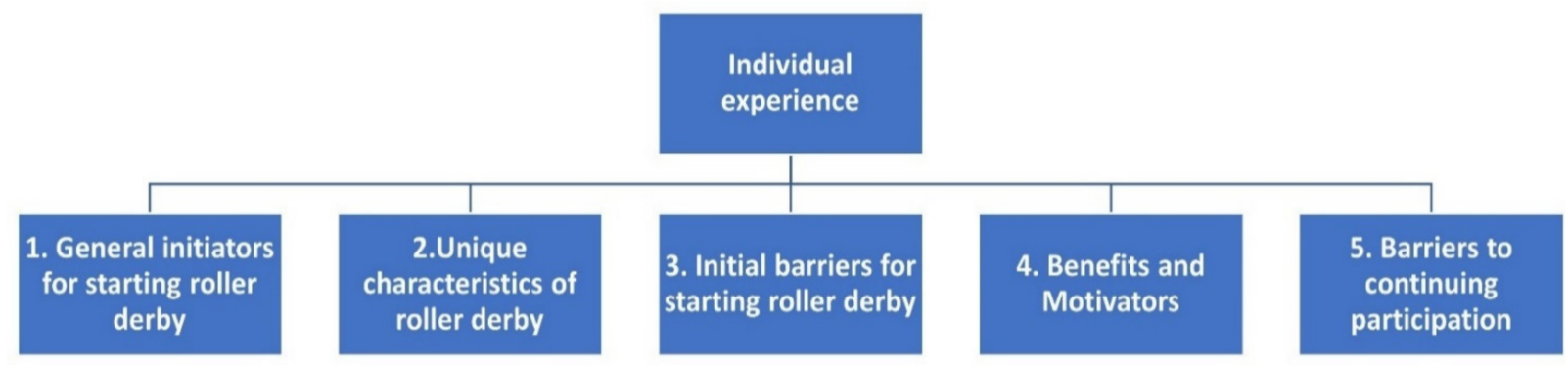

Figure 1. Overview of super-ordinate themes.

\subsection{Super-Ordinate Theme 1: General Initiators for Starting Roller Derby}

Participants explained roller derby's appeal. Four skaters described more general reasons for getting into roller derby. They discussed wanting to: meet new people, find a new hobby, and join a team sport. One participant felt there were few sport options in her city. The theme of taking part in sport to meet new people was expressed by two participants. These women had just moved cities. Zoe explained (1-5 years): “I arrived in the UK ... and knew nobody. And then I thought right I'm staying here and I need to meet people through a regular activity." Most participants felt they had few sport options available while growing up. Two participants enjoyed roller derby because it is a team sport. Both women participated in team sports at school and university. Three out of six women had been a member of a sports team before playing roller derby. Those who were drawn to the team aspect explained that they were motivated to exercise when there is a social aspect. One participant acknowledged that the full contact aspect is appealing. Zoe said (1-5 years): "Team sports on skates, full contact, the atmosphere, and the intensity of the sport all appealed." Three people stated that they were looking for a new hobby. One participant was disappointed in the lack of sport options available in Scotland. Zoe said (1-5 years): "The [mentions the city she lives in] sport scene for women is not great! There is lots of sport at university level but then there is nothing!"

\subsection{Super-Ordinate Theme 2: Unique Characteristics of Roller Derby}

The unique characteristics of this sport were discussed enthusiastically in five interviews and these impacted both on its initial appeal and motivation to continue participating. All individuals described their enjoyment of skating. The "cool" image of this sport was frequently mentioned. One person appreciated the "counterculture" spirit within the sport. Furthermore, a sense of a unique atmosphere within roller derby culture was often referenced. Skaters valued the DIY (do-it-yourself) ethos of this sport. They appreciated that this sport is new and women-driven, allowing them to have control over the direction of the sport. 
Roller derby has featured in an array of magazine articles, television shows, and films. This may have led to roller derby being regarded as a "cool" sport. The film "Whip It" (2009) initially inspired some participants to join. Zoe said (1-5 years): "It's a very clichéd answer, but I first found out about roller derby by watching "Whip It" and I thought this looks amazing ..." Participants described how they liked the look and style of the sport. Louise said (3-6 months): “ . . . they've got the cool black outfits and it looks just amazing ... " Some participants mentioned not belonging in mainstream sports. They found a sense of belonging in roller derby which was a motivator of ongoing participation. Louise explained: "I remember going to practice and everyone was wearing Doc Martins (boots) and I thought, ah these are my people." Roller derby often presents a queer-positive public image, which helped one participant feel more comfortable with her own sexuality. Louise said (3-6 months): "It's been very influential in my life. I've known I was gay for a long time and never told anyone but since going there [training] people are so open and it's all so cool." Louise added (3-6 months): "It's one of the first sports to be cool with transgender and it's very progressive." Roller derby presents itself as a progressive and increasingly inclusive alternative sport, with changes to the WFTDA's official policy on gender inclusion (2016), clarifying that the organisation is: "committed to inclusive and anti-discrimination practices in relation to all transgender women, intersex women, and gender expansive participants ..."

For most participants, the incorporation of skating into a sport was appealing. Emily said ( $>5$ years): "I love spinny things and apex jumps [skater cuts the inside track by jumping over it], it makes me so excited to do stuff like that." Participants were aware of a unique atmosphere when attending roller derby games and training sessions. Louise said (3-6 months): “It's a really cool world that I've just stumbled upon ... and I can't believe it's been going for years and I've not been a part of it."

Joining a sport that is new was a motivating factor for two experienced skaters. Roller derby might be more accessible than other sports later in life because most people start with no prior knowledge or skill. Amy commented on this initial draw (3-6 months): "You can go into it [roller derby] not knowing much about it, because most people don't know much about it. Most clubs as an adult, you are expected to have played before." Another participant felt fortunate to be part of a new sport that is continuously evolving and owned by the skaters. Emily explained ( $>5$ years): "Other sports have this top down, men-in-suits in a boardroom situation telling everyone what they can and can't do ... We are so lucky to be part of this sport when it's developing and it's in this grassroots state."

For the two longest-serving skaters, the league being owned and operated by the skaters was important to their ongoing participation. This ensures that skaters have control over their athletic activity, their leagues, and the sport as a whole. Emily said ( $>5$ years): “I wouldn't be happy if it was not DIY ... I would mourn it. I don't think it could happen without a massive fight." When asked about the recent introduction of men's roller derby, participants had no issues with this. Emily explained why there is little animosity between female and male leagues. She said ( $>5$ years): "There is a sense of taking a knee [paying respect] to women's roller derby and a graciousness and gratefulness about it. They [men's leagues] have allowed us to have our space because the fear was that they were just going to take over."

\subsection{Super-Ordinate Theme 3: Initial Barriers}

The most frequently mentioned initial barrier was having other commitments. Two people stated that university and work influenced their decision to delay participation. Amy said (3-6 months): "I work as a freelance [mentions her profession] ... If I had something else pulling my attention, I'm not sure I would have got much work." Injuries are common. One participant commented on initially feeling anxious about injuries. Zoe said (1-5 years): "At first I was worried about getting injured so delayed the process, but when I got involved, I loved it." Another participant initially dismissed roller derby because of the theatrical elements ingrained in the sport in its early days. Emily said ( $>5$ years): "My 
boyfriend had seen it ... and completely dismissed it on the basis that it was all fishnets and short skirts, and that was never my thing."

\subsection{Super-Ordinate Theme 4: Benefits and Motivators to Continue Participating in Roller Derby}

Participants explained why they are (or were) motivated to continue playing roller derby, as well as discussing the benefits that come from participation. The challenge, motivation to exercise, unwillingness to let other members of the team down, and obsession with the sport were all mentioned as motivators to participation. Furthermore, participants commented on the benefits of their involvement with the sport, including enjoyment, increased confidence, and health benefits. These benefits were also motivators for continued involvement.

The 'challenge' was an important theme expressed by all participants. Roller derby presents a unique opportunity to work hard towards individual and team goals. Others described the satisfaction of being able to cope with the "tough" aspects of the sport (for example, being hit, and the intensity of training). Participants enjoyed pushing themselves. Amy said (3-6 months): "I think it's a rare opportunity to work your ass off and you have to go for it ... I recognise that when I do something hard I always feel better about myself afterwards." Others described more personal goals. Lisa said ( $>5$ years): "Everyone has their own milestones ... everyone has their own thing to get over." In contrast, another skater discussed more shared goals as part of a team and league. Emily said ( $>5$ years): "Having a shared goal of being somewhere and getting there ... to me, it's about getting better and pushing myself and pushing each other." Participants described the satisfaction of being able to take a hit and give a hit. Zoe said (1-5 years): "Derby is hard, and you need to take the hit and that's why people love it." Another participant discussed how roller derby culture celebrates injury and pain. Louise said (3-6 months): "People like to show off their bruises like in "Whip It". It's like our battle wounds."

All participants discussed their enjoyment of the sport. They commented on enjoying the intensity, competition, and the strategic aspect of the game. Nicola said ( $>5$ years): "It does attract competitive people to put it mildly. I'm very competitive and I like that aspect." Increases in physical, psychological, and social confidence were highlighted by all of the participants, revealing how participation can potentially enhance quality of life. The women described feeling empowered from being skilled in the hitting aspect of the game. Lisa said ( $>5$ years): "I found it good to be feared! I could knock them over and thought, this is great! I enjoyed the hitting and hearing the crowd roar." Some participants experienced an increase in body confidence with participation in roller derby. Participants began to evaluate their bodies based on how they perform on track, rather than appearance. Lisa said ( $>5$ years): "I think the experience has been completely invaluable. For someone who was never sporty and struggled with weight all my life, to be able to do something like that and use this body that I had never really thought was good for anything." Emily felt more emotionally confident ( $>5$ years): "I feel strong and empowered and capable, and emotionally I am a lot more confident." Confidence also increased from taking part in committee work and developing organisational skills.

Improved mental, physical, and social health benefits were described by all participants. Lisa said ( $>5$ years): "It got me through a difficult period of my life. It was a reason to keep going and make training ... that was something I will always be thankful for." Some participants felt fitter from training regularly. Skaters are expected to do strength and conditioning training ("off-skates" training) in addition to skating practice. All participants commented on the social benefits that come from involvement. There is a strong sense of community and camaraderie. Emily explained ( $>5$ years): "Most of our friends [refers to partner] are from derby so we met people who are really important to us ... Having a group of strong women that I can go to or look to for support ... I've never been a girl's girl and we are kind of similar." One skater who retired described wanting to take part in another sociable sport. Zoe said (1-5 years): "Most people join fitness clubs which I find 
boring ... there's no social aspect ... that's why it's [roller derby] such a good sport. I'm still looking for something."

For some, the unwillingness to let others down was a motivator for continued participation. Emily explained ( $>5$ years): "People rely on me ... If you are part of a team, then others are relying on you to be there. Also, people are relying on me for lifts ... Others keep me going." Others explained how their exercise levels rose significantly since taking part because it is a fun way to exercise. All participants were motivated to join a gym in order to improve their athletic performance. Three skaters would never have considered joining a gym. Nicola said ( $>5$ years): "It is really fun. You feel like you're not exercising even though you are ... I would never go to the gym. But if you asked me to go to the gym and lift weights for roller derby, I think yeah ok I can do that. There is a self-motivation to do better."

Participants (excluding new skaters) spoke of feeling or having felt obsessed with roller derby. The deeper participants had immersed themselves in the sport and culture, the more difficult it became to leave. Nicola said ( $>5$ years): "I love my league and the sport. I am all-consumed ... " Skaters are expected to train at least twice a week (three if drafted to the A team), do one hour of committee work each week, and also focus on off-skates training. Current skaters described how their social circle became included in roller derby. Nicola said ( $>5$ years): "My former flatmates were skaters in the league and also my sister... Your social circle becomes smaller and you see people outside derby less." Skaters who had been there longer than five years held key roles within the league: skating on the A team and heading committees. They both described working towards personal and shared goals. Emily said ( $>5$ years): "Having a shared goal of being somewhere and getting there ... it's about getting better and pushing myself and pushing each other."

\subsection{Super-Ordinate Theme 5: Individual Barriers to Participation}

The researcher was fortunate in being able to interview people who no longer participate in the sport. Barriers were mostly linked to the individual and their relationship with the team, and the league as a whole. 'Logistics' was a minor theme. Difficulties with public transportation affected one skater. More general barriers included being injured which prevented participation, as well as logistical reasons. All participants discussed being injured or fear of injury. One participant (who had dropped out) discussed how being injured impacted on her motivation. Zoe said (1-5 years): "I stopped training for a long time. I was in a mixed period, and I didn't know what to do ... it damaged my motivation a lot." The issue of commitment was an important theme discussed by all skaters and refers to time commitment and a league culture that respects dedication to the sport. Skaters are expected to train several times a week and do committee work. New skaters mentioned that this was daunting. The A-team skaters found playing at a high level was very time-consuming. Former skater Lisa ( $>5$ years) discussed the challenges of having children and playing the sport: "They try and say that it's an inclusive thing but it's not. It's inclusive if you are willing to give up everything ... it wasn't accepting of people who had families. A lot of people [other league skaters] were put out by that because they weren't sacrificing enough to do this thing that they really enjoyed."

The theme of 'pressure' was prominent and emphasised by four participants. Two skaters experienced a significant amount of pressure (put on themselves) to succeed. Others commented on external pressures from being on a team and being part of a sport that wants to be taken more seriously. Former skater Zoe described setting high standards for herself and the frustration of failing to meet them. Zoe explained (1-5 years): "I put too much pressure on myself rather than coming from anyone else. I had high expectations and was not meeting them. Others were telling me to stop being so hard on myself." Former skater Lisa ( $>5$ years) wanted to give up her spot on the team before it was taken from her: "Anxiety started to come in with keeping my spot on the team." She added: "I wanted to leave on a positive note and before I got pushed out." Emily mentioned skaters dropping 
out after competing at a high level. Emily said ( $>5$ years): "High level skaters dropped out because we had burst ourselves. We had to work really hard ... it was high pressure ... For some it was too much." New skater Louise said (3-6 months): "I do like that intensity, but it's so intense ... it freaks me out at times. I think it you didn't go for it people would notice. There's no room for someone to just go and skate."

'Lack of support' was an important theme highlighted by the two participants who dropped out. Both participants felt unsupported by their team. One former skater felt let down by the league in terms of sharing the committee work. Zoe felt let down by her team when she was injured and put off the team. Zoe said (1-5 years): “ . . they put me off the charter without helping me out, because I was injured, and I felt dumped and isolated." Lisa felt socially isolated ( $>5$ years): "I felt like I was tolerated, and they would have rather had one of their own friends take my spot. I went from feeling part of something to feeling like I was on the outskirts." She added: "When my friends stopped going it became a struggle ... " All participants commented on the challenges of running the league. Three participants discussed how committee work was not evenly shared out. For Zoe, this led to feeling resentful towards other league members. Zoe said (1-5 years): "I needed a break because I was burning out a bit in [mentions league name] because I was doing far too much on the committee, there was lots of work and not much help."

\subsection{Conceptual Framework of Super-Ordinate Themes}

Further analysis led to the development of a conceptual diagram (Figure 2) that illustrates the connections between super-ordinate themes. Theme 3 includes initial barriers to starting roller derby. Reasons for starting participation in roller derby were split into two super-ordinate themes: the first being 'General Initiators for Starting Roller Derby' (1) and the second being 'Unique Characteristics of the Sport' (2). There are themes belonging to the second super-ordinate theme (e.g., 'DIY ethos' and 'skating') that link with the fourth super-ordinate theme 'Benefits and Motivators' (4) because they were both initiators for starting, and also benefits and motivators for continued participation. 'Benefits and Motivators' (4) are shown to lead to continued participation, and similarly 'Barriers' (5) lead to stopping participation. It is too simplistic to suggest, however, that all skaters will continue when experiencing the benefits of participation. There is likely to be an intermediate phase of evaluating the pros and cons before making a decision to continue or not.

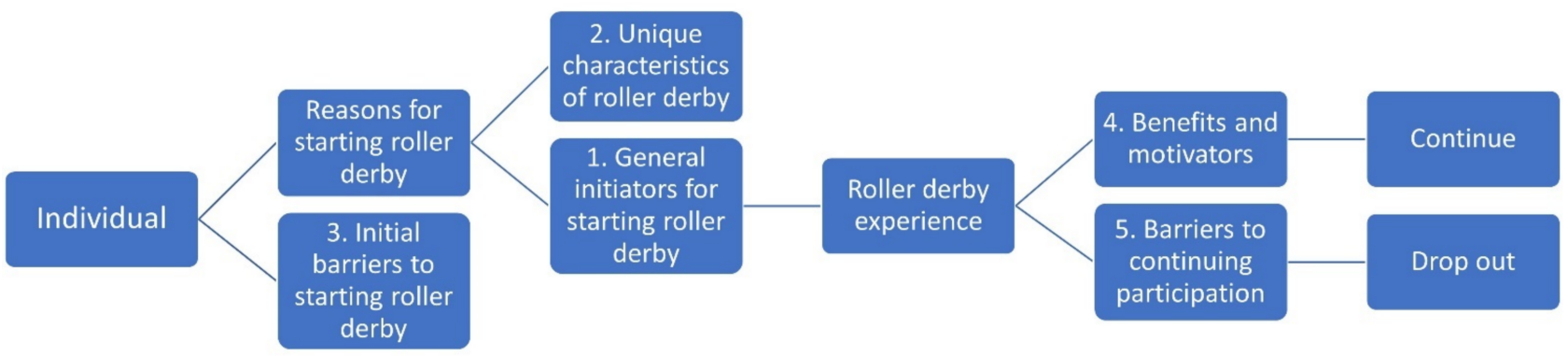

Figure 2. Conceptual framework of super-ordinate themes 1-5: "Individual Journeys through the Roller Derby Experience."

\section{Discussion}

This small-scale study has nonetheless generated novel and transferable insights into the reasons that women start, continue, and sometimes stop participating in roller derby. Reasons for starting to participate included its unique culture and close community. The unique characteristics of the sport attracted most participants, as roller derby is not just a sport, but a unique world presented as appealing by the media. Enjoyment of skating and a sense of a unique atmosphere also attracted people. Counterculture is at the heart of roller derby, and this sport tends to attract like-minded people who might not feel suited to more mainstream sports. Roller derby also circumvents some of the barriers, such as those 
relating to access, associated with sports traditionally dominated by men [8,16]. Roller derby has feminist appeal because of its central DIY ethos, valued by participants in this study as it enabled women to create an alternative to male-dominated sport: a womenowned and operated, democratic governance structure.

Roller derby is arguably more accessible than other sports for people who lack experience of team sports, because it is new, and most people have no previous experience. This may more readily enable experiences of success that impact positively on self-efficacy [33]. Some participants were already intrinsically motivated to participate in sports of different types for enjoyment and feelings of mastery, while for others, motivation to engage in sport was a new discovery in their lives, specific to roller derby. This is important, as a behaviour is far more likely to be sustained over time if it is intrinsically motivated, which has important implications in relation to ongoing health benefits.

Only one study [19] has touched on why women first become involved in roller derby. Our findings support their findings that roller derby can provide a 'safe' environment for people to explore physical and emotional capabilities. Experiences and social feedback may increase feelings of physical self-efficacy [33]. Participants were motivated to continue participating because of the challenge, enjoyment, and obsession with the sport. Some of the challenging and painful aspects of the sport were also signifiers of community, strength, competition, and toughness. Benefits were also motivators and included a range of health benefits, increased motivation, increased motivation to exercise, and an increase in confidence. Previous studies shared similar themes describing how the sport is empowering for women $[16,23-25,27,28]$. Enjoyment of the challenge and increased confidence from participation were also common findings [16,24,27,34].

It is possible that where women may have developed insecurities and a lack of identification with sports over time, roller derby provides a staged and well-supported entry, involving training and a sense of community. A previous study has found that both training and social support helped women to overcome barriers to initiating cycling [10]. Not having to overcome many challenges of a male-dominated sport may facilitate mastery and enjoyment, generating intrinsic motivation and increased likelihood of ongoing participation with associated health benefits.

Interviewing people who had stopped participating in roller derby was a valuable aspect of this study, highlighting the commitment required as a frequently mentioned barrier to continued participation, as well as lack of support, pressure to perform, and frustration due to injuries. Interestingly, some of these points were raised as concerns that were initial barriers to roller derby. It was particularly apparent that life stage is important, a point raised in the wider literature about women and sport [12,13]. In our analysis, this appeared to be more important than age as increases in participants' commitments to work and to family influenced their ability to commit to roller derby, and such changes do not necessarily correlate with age. It is possible that people who stop participating have had such gains in self-efficacy and intrinsic motivation for exercise and sport that they seek other ways of participating that are easier to integrate into their lives. It may be natural to change one sport for another that is more possible to sustain due to changes in one's commitments and interests, and this might be supported where a person has had positive recent experiences of the journey of roller derby participation. This may be partially supported by our finding that some participants were inspired to further strength and conditioning training as a tool to increase their roller derby performance. There has been little discussion in the literature on the exercise drive that comes from roller derby participation, and the significant amount of time and effort that women put into improving their fitness. The possibility that roller derby acts as a facilitator to engagement in different forms of physical activity, for people who may have previously lacked confidence and avoided such situations, is worth further exploration. It is possible that roller derby provides a 'safe space' for pushing one's physical boundaries in a mutually supportive and accepting world, opening people up to other possible forms of movement once the intense nature of the sport can no longer be accommodated in their lives. It may be difficult, 
however, to find another activity with a built-in social element and community such as roller derby.

A further important finding from those who had stopped participating related to the impacts of the high levels of commitment required. Few studies convey how the sport can become all-consuming. Skaters can lose touch with relationships outside of roller derby and those who left felt excluded. It appears that those who prioritise other commitments outside roller derby may find themselves less accepted and valued in a sport that otherwise values diversity. This is an interesting finding, as most people experience changing priorities and roles in their lives. These can be very influenced by the cultural influences around them. Women may enjoy the empowerment of roller derby and its rejection of male dominance; this does not mean, however, that they are immune to this in the rest of their lives. McGannon and Schinke highlighted the impacts that a patriarchal discourse can have on parenting and domestic roles, for example [13]. Motherhood is often linked with self-sacrifice that affects leisure time differently between men and women-even with a more equal partnership, the time and energy required for parenting may challenge the levels of commitment needed for roller derby.

The lack of support for people to continue roller derby with less commitment may have implications both for health and for the promotion of women in sport. Firstly, if the unique aspects of roller derby were very important in overcoming barriers to sport for a particular woman, it may be very difficult for her to find an alternative. Lack of ongoing physical activity participation will lead to the loss of health benefits over time. Secondly, loss of women to the sport as they develop other life roles may waste a valuable opportunity. For example, parents are crucial role models as children develop: boys can learn to respect the physical and leadership capabilities of women in sport, as highlighted by Channon in relation to mixed martial arts and combat sports [35]. After interviewing 37 men and women who frequently trained together, some men described having 'grown up' with women in positions of authority and seniority in relation to their training. This had profoundly affected their perceptions of women in the sport and challenged stereotypes relating to femininity. Similarly, girls can be inspired by women in their lives to view physical strength and capability as feminine, to see themselves as having access to the sporting world, and to believe that changing roles in life need not challenge this.

As a result of these findings, we argue that while some leagues already have a more recreational focus, this could be considered by all. Inclusivity should be addressed in relation to life stage as well as many other aspects of a person. There may be ways of enabling ongoing recreational roller derby, with regular but short-term competitive opportunities for higher levels of commitment that celebrate the skills and experience of women who have otherwise reduced their commitment over time. This would enable women to demonstrate the skills they have developed to themselves, the people in their lives and in the leagues, and engage in ongoing physical activity that they enjoy, while navigating increasingly complex and interacting commitments in their lives. It could help to role model a more positive commentary about the body, as discussed by Paul [9] in his grounded theory study of 17 women engaged in roller derby, mixed martial arts, and rugby. Therefore, we propose that supporting ongoing involvement in roller derby could impact positively on health, while increasing the respect that boys and then men have for women in sport and helping to inspire young women to enter sport and flourish in a sense of identity as a woman who is physically powerful and resilient.

\section{Study Considerations and Limitations}

It is important to consider that the data for this study were collected in 2016. Despite the normal time lag in research publication, this can be considered a limitation. In the current COVID-19 pandemic context, however, we feel that the importance of understanding ways of supporting women to engage in active and empowering community experiences is even more important. As people are increasingly re-engaging with community activities, it 
will be important to explore impacts of the past two years on women's motivations and barriers to participating in roller derby and physical activity more generally.

This study recruited a mixture of participants currently participating and those who dropped out. Context has been described to enable readers to consider transferability to their setting carefully, as this study included six participants from one league. This study provides new insights into the experiences of women participating in roller derby, and further international studies are warranted that explore how recruits are integrated into the league, and how changes in levels of commitment are negotiated. Given the evidence that roller derby can be empowering for women, further exploration of the experiences of young girls participating in junior roller derby leagues would be useful to determine the impact it might have on self-esteem and body image. It would be valuable to talk with more people who have stopped participating in roller derby and those who have returned to the sport after a period of time to explore influences, strategies, and whether there have been any enduring impacts on their decisions and perceptions relating to physical activity or exercise. Key future questions could include: does the experience of having built physical and emotional confidence through engaging in roller derby increase a woman's likelihood of starting/continuing with another sport? Does the way in which a person leaves roller derby affect this?

\section{Conclusions}

Roller derby was an enjoyable and invaluable experience for the women who took part in this study. Similar to previous studies, roller derby was found to improve confidence, provide an enjoyable way to exercise, and generate a sense of inclusion in a community which celebrates diversity. The unique characteristics of this sport attracted most of the women to the sport, but also contribute to a risk of people being unable to sustain the consuming nature of commitment involved as life roles change. When people stop participating, they may be negatively affected by feeling excluded and potentially by reduced physical activity with loss of the health benefits. It is possible that an increased sense of sporting identity and body confidence positively affect women's resilience in relation to trying other forms of physical activity and exercise, which requires further exploration. Roller derby leagues could explore further ways of including and supporting women when injured or unable to sustain the same levels of commitment. This could have far-reaching benefits for the health of those participating and their impacts on people in their lives. While this study started with a focus on health, the complex interactions between sport and women's sense of identity as affected by cultural stereotypes and by life changes mean that they have to be considered as part of a wider discussion.

Author Contributions: Conceptualisation, methodology, analysis, writing, review and editing, J.S. and C.B.; data collection, J.S.; supervision, C.B. All authors have read and agreed to the published version of the manuscript.

Funding: This research received no external funding.

Institutional Review Board Statement: The study was conducted according to the guidelines of the Declaration of Helsinki and approved by the Queen Margaret University Divisional Ethics Committee.

Informed Consent Statement: Informed consent was obtained from all subjects involved in the study.

Data Availability Statement: The data presented in this study are available upon request from the corresponding author, subject to appropriate ethical review, due to the risks of identifiability through combined data.

Conflicts of Interest: The authors declare no conflict of interest. 


\section{References}

1. United Nations (UN). Women, Gender Equality and Sport: 2000 and Beyond; United Nations Division for the Advancement of Women Department of Economic and Social Affairs: New York, NY, USA, 2007. Available online: http:/ /www.un.org/womenwatch/ daw/public/Women\%20and\%20Sport.pdf (accessed on 9 December 2021).

2. National Health Service. Benefits of Exercise. NHS; Crown Copyright: London, UK, 2016. Available online: http://www.nhs.uk/ Livewell/fitness/Pages/Whybeactive.aspx (accessed on 9 December 2021).

3. Minton, J.; Shaw, R.; Green, M.A.; Vanderbloemen, L.; Popham, F.; McCartney, G. Visualising and quantifying 'excess deaths' in Scotland compared with the rest of the UK and the rest of Western Europe. J. Epidemiol. Community Health 2016, 71, 461-467. [CrossRef] [PubMed]

4. Scottish Government. The Scottish Health Survey: Main Report, Volume 1; Scottish Government: Edinburgh, Scotland, 2014. Available online: http:/ / www.gov.scot/Publications/2015/09/6648 (accessed on 9 December 2021).

5. World Health Organzsation. Physical Inactivity: A Global Health Problem; World Health Organization: Geneva, Switzerland, 2016. Available online: http:/ / www.who.int/dietphysicalactivity/factsheet_inactivity/en (accessed on 9 December 2021).

6. Van Tuyckom, C.; Scheerder, J. Sport for All? Insight into stratification and compensation mechanisms of sporting activity in the 27 European Union member states. Sport Educ. Soc. 2010, 15, 495-512. [CrossRef]

7. Sport England. Understanding Participation in Sport: What Determines Sports Participation among 15-19 Year Old Women? Sport England: London, UK, 2006. Available online: https://www.sportengland.org/media/3323/understanding-participationamong-15-19-year-old-girls-summary-report.pdf (accessed on 9 December 2021).

8. Stirling, L.; Schulz, J. Women's Football: Still in the hands of men. Sport Manag. Int. J. 2011, 7, 55-77.

9. Paul, J. Sport and bodily empowerment: Female athletes' experiences with roller derby, mixed martial arts, and rugby. J. Alt. Perspect. Soc. Sci. 2015, 6, 402-438.

10. Rowe, K.; Shilbury, D.; Ferkins, L.; Hinckson, E. Challenges for sport development: Women's entry level cycling participation Sport Manag. Rev. 2016, 19, 417-430. [CrossRef]

11. Trecroci, A.; Invernizzi, P.L.; Monacis, D.; Colella, D. Actual and Perceived Motor Competence in Relation to Body Mass Index in Primary School-Aged Children: A Systematic Review. Sustainability 2021, 13, 9994. [CrossRef]

12. Maher, J.H.; Lowe, J.B. Navigating health priorities and motivators during pregnancy and new motherhood. Nutr. Diet. 2015, 72 , 333-339. [CrossRef]

13. McGannon, K.R.; Schinke, R.J. "My first choice is to work out at work; then I don't feel bad about my kids": A discursive psychological analysis of motherhood and physical activity participation. Psychol. Sport Exerc. 2013, 14, 179-188. [CrossRef]

14. Office for National Statistics. Leisure Time in the UK: 2015; ONS: London, UK, 2015. Available online: https://www..ons.gov.uk/ economy/nationalaccounts/satelliteaccounts/articles/leisuretimeintheuk/2015 (accessed on 9 December 2021).

15. British Broadcasting Corporation. Roller Derby World Cup: Six Things We Learned in Manchester; BBC: London, UK, 2018. Available online: https:/ / www.bbc.co.uk/sport/42944801 (accessed on 19 January 2022).

16. Paul, J.; Blank, S. The power and joy of derby: Women's participation, empowerment, and transformation in a flat-track roller derby team. J. Fem. Scholarsh. 2015, 9, 51-72.

17. World Flat Track Derby Association. WFTDA Leagues; WFTDA: Austin, UK, 2018. Available online: https://wftda.com/wftdaleagues/\# (accessed on 9 December 2021).

18. Breeze, M. There's No Balls in Derby: Roller Derby as a Unique Gendered Sports Context. Int. J. Sport Soc. 2010, 1, 121-133. [CrossRef]

19. Breeze, M. Seriousness and Women's Roller Derby: Gender, Organisation, and Ambivilence; Palgrave McMillan: London, UK, 2015.

20. Hoskins, A.L.; Hooker, R.S. Sudden Impact: Concussion in Female Roller Derby Athletes. Ann. Sports Med. 2015, 2, 1-5. [CrossRef]

21. Ecklund, A.; Masberg, B.A. Participation in Roller Derby, the Influence on Body Image. Cloth. Text. Res. J. 2014, 32, 49-64. [CrossRef]

22. Alexander, J. On the Outskirts?: Exploring the Sydney Roller Derby Scene. Ph.D. Thesis, Western Sydney University, Sydney, Australia, 2016. Available online: http:/ / researchdirect.westernsydney.edu.au/islandora/object/uws\%3A44522 (accessed on 9 December 2021).

23. Carlson, J. The Female Significant in All-Women's Amateur Roller derby. Sociol. Sport J. 2010, 27, 428-440. [CrossRef]

24. Finley, N.J. Skating Femininity: Gender Maneuvering in Women's Roller Derby. J. Contemp. Ethnogr. 2010, 39, 359-387. [CrossRef]

25. Beaver, T. "By the skaters, for the skaters." The DIY Ethos of the Roller Derby Revival. J. Sport Soc. Issues 2012, 36, 25-49. [CrossRef]

26. Gieseler, C. Derby Drag: Parodying sexualities in the sport of roller derby. Sexualities 2014, 17, 758-776. [CrossRef]

27. Pavlidis, A.; Fullager, S. Sport, Gender and Power: The Rise of Roller Derby, 1st ed.; Routledge: Surrey, UK, 2014.

28. Storms, C.E. "There is no sorry in roller derby": A feminist examination of identity of women in the full contact sport of roller derby. N. Y. Sociol. 2008, 3, 68-87.

29. Murray, M. The Unladylike Ladies of Roller Derby?: How Spectators, Players and Derby Wives Do and Redo Gender and Heteronormativity in All-Female Roller Derby. Ph.D. Thesis, University of York, York, UK, 2012. Available online: https: / / core.ac.uk/download/pdf/5225545.pdf (accessed on 9 December 2021).

30. Smith, A.S.; Flowers, P.; Larkin, M. Interpretative Phenomenological Analysis: Theory, Method and Research; SAGE: London, UK, 2009.

31. Moule, P.; Hek, G. Making Sense of Research: An Introduction for Health and Social Care Practitioners, 4th ed.; SAGE: London, UK, 2011. 
32. Gentles, S.J.; Charles, C.; Ploeg, J.; McKibbon, K.A. Sampling in qualitative research: Insights from an overview of the methods literature. Qual. Rep. 2015, 20, 1772-1789. [CrossRef]

33. Bandura, A. Self-Efficacy: The Exercise of Control; Freeman: San Francisco, CA, USA, 1997.

34. Pavlidis, A.; Fullager, S. Narrating the Multiplicity of 'Derby Grrl': Exploring Intersectionality and the dynamics of affect in roller derby. Leis. Sci. 2013, 35, 422-437. [CrossRef]

35. Channon, A. Towards the "undoing" of gender in mixed-sex marital arts and combat sports. Societies 2014, 4, 587-605. [CrossRef] 